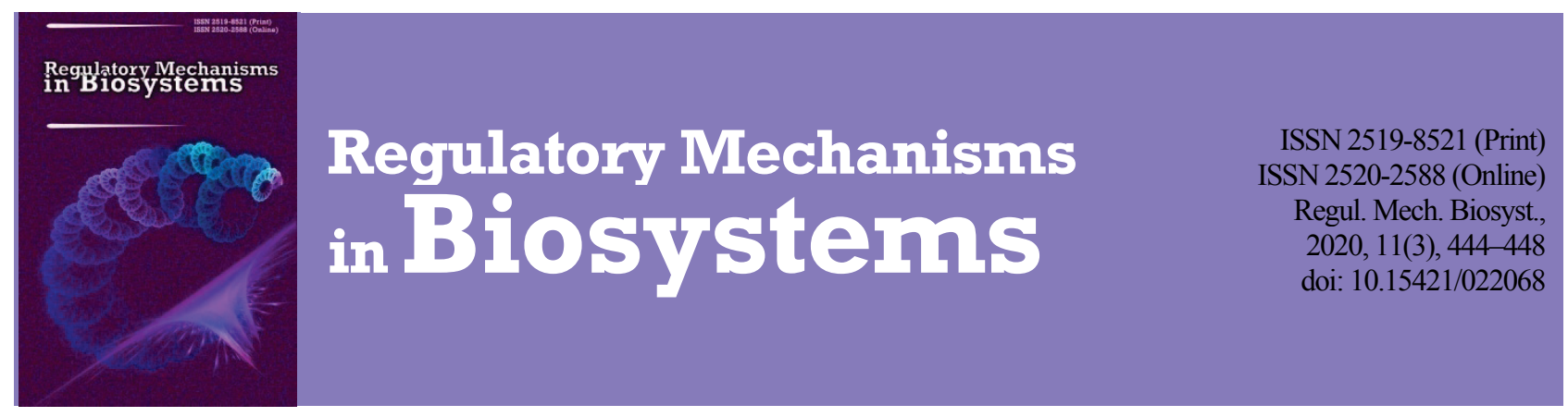

\title{
Distribution of sturgeon in the River Irtysh
}

\section{A. A. Chemagin}

\author{
Tobolsk Complex Scientific Station UrB RAS, Tobolsk, Russia
}

Article info

Received 04.07.2020

Received in revised form 08.08 .2020

Accepted 09.08 .2020

Tobolsk Complex

Scientific Station UrB RAS

acad. Y. Osipov st., 15 ,

Tobolsk, 626152, Russia.

Tel.: +7-982-923-99-40.

E-mail:

ChemaginAA@yandex.ru

Chemagin, A. A. (2020). Distribution of sturgeon in the River Irtysh. Regulatory Mechanisms in Biosystems, 11(3), 444-448. doi:10.15421/022068

Using the modern hydroacoustic methods and the computerized software and hardware complex "AsCor", the features of the distribution of fish of the Acipenseridae family in the lower reaches of the large transboundary river the Irtysh (Western Siberia) have been investigated: in the water area of the riverbed depression (turbulent flow) and control sections (laminar flow). The identification of sturgeon was carried out by the echometric method according to the shape of the swim bladder. It is shown that in the water area of the riverbed depression, increased density of fish is formed, the share of sturgeons being 4.9-5.8\%. Among other fish species, the group of cyprinids always dominates. The significant excess of the average fish density in the riverbed depression, in contrast to the control, was 6-30 times. In the water area of the riverbed depression, the average fish density was 4,524, in the control sections 245 2,091 individuals/ha. The size structure of the group of sturgeon in the control sections was represented by individuals with body sizes less than $25-30 \mathrm{~cm}$, and in the riverbed depression - by individuals of different sizes and ages with a body length to $35 \mathrm{~cm}$. The water area of the riverbed depression is located in the meandering section of the river and is characterized by intense vertical vortex structures (whirlpools) and the presence of malfunctioning currents. Features of the hydrological characteristics of the riverbed depression are factors in the formation of aggregations of fish, since fish can use the energy of discrete vortices, low-velocity areas, and as a result, show preference for certain turbulence regimes.

Keywords: riverbed depression; aggregation of fish; Ob-Irtysh basin; Acipenseridae; turbulence.

\section{Introduction}

A quantitative assessment of the movements of animals, including aquatic organisms, can reveal the spatial and temporal patterns of habitat use as a result of the influence of various factors, which in turn contributes to a greater understanding of their foraging strategies (Altenritter et al., 2013; Marenkov, 2018), the finding of optimal conditions for somatic growth (Nakayama et al., 2018) and shelter from predators (Muška et al., 2013), etc.

The study of the influence of environmental characteristics and their dynamics makes it possible to determine the sections of aggregations for aquatic organisms, facilitating their registration and monitoring, including rare and endangered fish species (Bogdanov \& Mel'nichenko, 2011, Thayer et al., 2017; Andrews et al., 2020;). The formation of aggregations of fish can be influenced by the features of the bottom morphology, hydrological characteristics (Pavlov et al., 2010; Bogdanov \& Mel'nichenko, 2011; Westrelin et al., 2017; Thayer et al., 2017), availability of prey (Holubová et al. 2019).

In this regard, the purpose of the work is to determine the features of the distribution of sturgeon fish in the lower reaches of the Irtysh River, including the riverbed depression and control rectilinear sections.

\section{Methods}

The studied sections of the river are located in the lower reaches of the Irtysh River near the village of Uki, Uvat District, Tyumen Region (Western Siberia, Russian Federation) (Fig. 1).

The water area of the riverbed depression and control river sections are located in coordinates: $58.857600^{\circ}$ N.L., $68.742267^{\circ}$ E.L. - riverbed depression, $58.853681^{\circ}$ N.L., $68.716809^{\circ}$ E.L. - control river section №1, $58.856008^{\circ}$ N.L., $68.758043^{\circ}$ E.L. - control river section №2, $58.863373^{\circ}$
N.L., $68.758391^{\circ}$ E.L. - control river section №3, 58.861899 ${ }^{\circ}$ N.L., $68.718168^{\circ}$ E.L. - control river section №4 (Fig. 2).

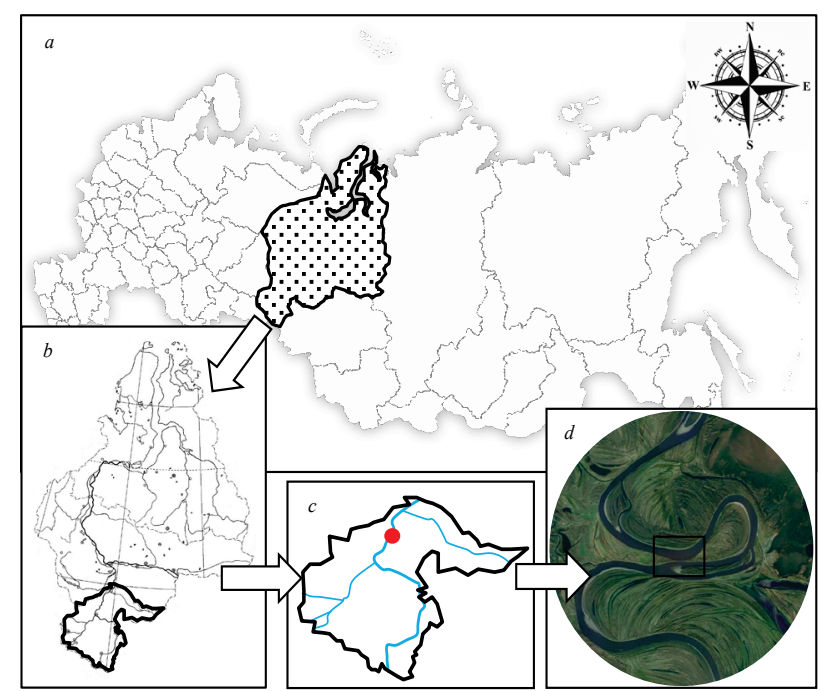

Fig. 1. Schematic map of the study area:

$a$-Russian Federation; $b$-Tyumen region; $c$-Locality of the riverbed depression; $d$-Satellite image of the locality of the riverbed depression

For hydroacoustic surveys, we moved along the water area of the studied sections the rivers along the tack grid according to generally accepted techniques (Yudanov et al., 1984). Research was carried out by sonar method using a computerized acoustic complex "Ascor" (LLC "Promgidroakustika", Petrozavodsk) during the period: May 1, 2020, May 10, 2020, May 27, 2020. The operation of the complex is based on the use of a serial two-beam echo sounder Furuno LS 4100 (Furuno Inc, Japan) with 
operating frequencies of 50 and $200 \mathrm{kHz}$. The complex also includes an analog-to-digital converter (ADC) unit, with the help of which the data of the receiver-transmitter (antenna) of the echo sounder are recorded in the form of a file on a protected field tablet.

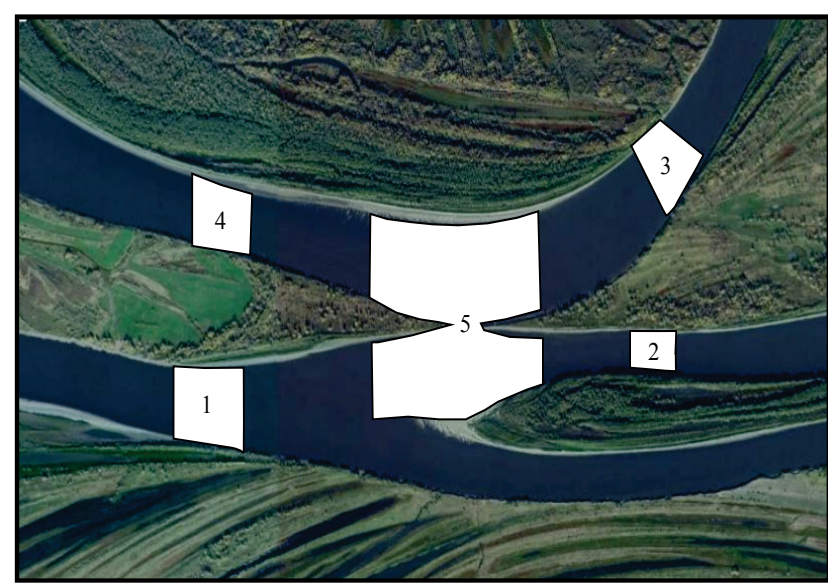

Fig. 2. Schematic map of the location of the formed channel pit and control sections: 1-4-control river sections, 5-riverbed depression

The hydroacoustic survey data were processed using the "AsCor" software, in which the body length of the registered fish was also determined. Taxonomic identification of ichthyofauna according to the results of echometric sounding in the studied river areas was carried out based on the shape of the swim bladder (Borisenko et al., 2006) in the laboratory using the "Taxonomy" program; the group of sturgeon and burbot can be distinguished by the tube-shaped bladder. It should be noted that the burbot (Lota lota Linnaeus) was not active during the study period, its regis- tration was difficult, therefore, among this group of fish, mainly representatives of sturgeon were noted. Hydroacoustic survey was used to determine the density of fish, their taxonomic composition, as well as to determine the depth and morphology of the bottom. To create a relief and bathymetric map of the bottom in the water area of the riverbed depression, we used geoinformation programs: Google Earth Pro 7.3.3 ("Google Inc.", USA) to export a satellite image for the base map - MapWiever 6.0 and Surfer 6.0 ("Golden Software", USA) for digitizing the base of the terrain map and creating bathymetric and relief maps of the bottom by interpolation method "Inverse distance to a Power" (Zimmerman et al., 1999) in format World Geodetic System 1984. Statistical data processing was carried out in the program Statistica 10.0 ("Statsoft", USA).

To control the species composition of the ichthyofauna, control fishing was performed with fixed and flowing gill nets.

\section{Results}

In 2019, in the studied area of the Lower Irtysh, as a result of the erosional action of the flow in conjugate meanders, we noted one of the stages of the loop-shaped ( $\omega$ - shaped) evolution of the channel: erosion of the isthmus and confluence of channel sections with intense erosion of the river bed, as a result of which a deep section of the channel is formed (Fig. 2,3). As a result of hydroacoustic surveys and the creation of bathymetric maps of the formed riverbed depression, it was found that during the study period the maximum depth marks were more than $27 \mathrm{~m}$, the deepest part was noted in the left-bank erosion zone in the meander (bend) section with mutually penetrating flows (Fig. 3). As a result, of the interaction of counter flows, vertical vortex structures (eddies) are formed and further erosion of the channel was observed downstream of the eroded isthmus zone between sections of the channel. Thus, a complex heterogeneous turbulent environment was formed in the zone of the wintering riverbed depression. (Fig. 3)
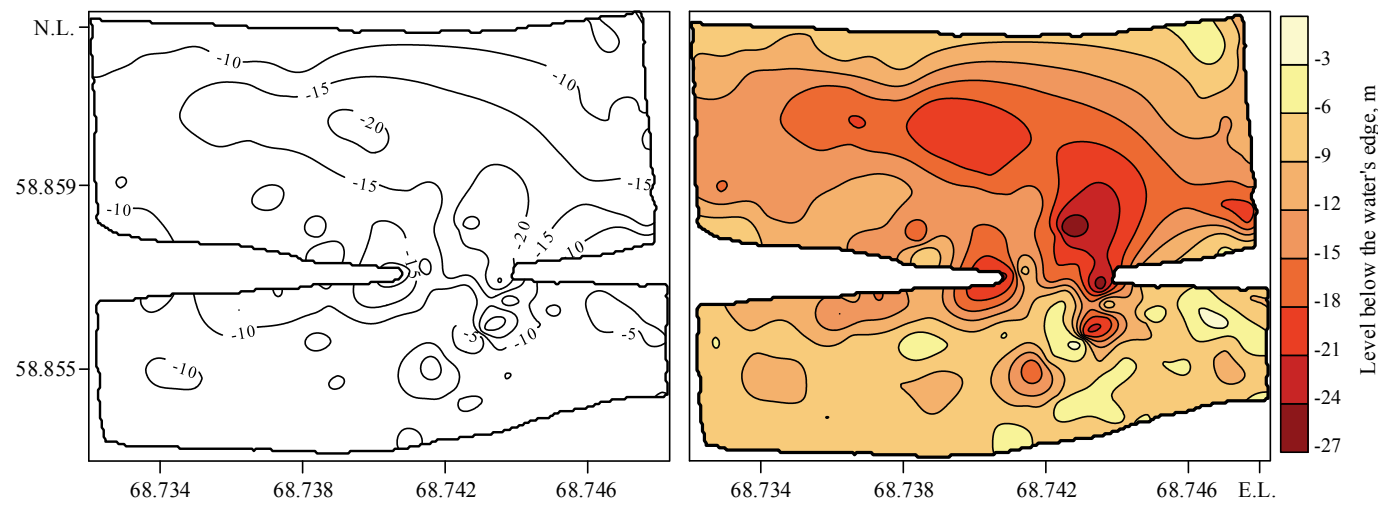

Fig. 3. Bathymetric (left) and relief map (right) of the bottom surface of the deep part of the wintering riverbed depression

Table 1

Ratio of the registered size groups of Acipenseridae in the water area of the riverbed depression and control sections of the Irtysh River (May 2020)

\begin{tabular}{|c|c|c|c|c|c|c|c|c|c|c|}
\hline \multirow{2}{*}{$\begin{array}{l}\text { Studied sections } \\
\text { of the river }\end{array}$} & \multirow{2}{*}{ Observation date } & \multicolumn{8}{|c|}{ Share of fish size groups, $\%$} & \multirow[b]{2}{*}{ Total } \\
\hline & & $<5$ & $5-10$ & $10-15$ & $15-20$ & $20-25$ & $25-30$ & $30-35$ & $>35$ & \\
\hline \multirow{3}{*}{ Riverbed depression } & May 1 & 6.5 & 44.5 & 26.5 & 7.7 & 5.2 & 2.5 & 3.2 & 3.9 & 100 \\
\hline & May 10 & 5.8 & 50.6 & 30.7 & 7.1 & 4.3 & 0.3 & 0.9 & 0.3 & 100 \\
\hline & May 27 & 2.9 & 52.2 & 32.4 & 6.8 & 2.1 & 0.7 & 1.1 & 1.8 & 100 \\
\hline \multirow{3}{*}{$\begin{array}{l}\text { Control river section } \\
\text { No. } 1\end{array}$} & May 1 & 16.7 & 50.1 & 8.3 & 8.3 & 8.3 & 0 & 0 & 8.3 & 100 \\
\hline & May 10 & 0 & 0 & 100.0 & 0 & 0 & 0 & 0 & 0 & 100 \\
\hline & May 27 & 8.2 & 69.4 & 18.3 & 4.1 & 0 & 0 & 0 & 0 & 100 \\
\hline \multirow{3}{*}{$\begin{array}{l}\text { Control river section } \\
\text { No. } 2\end{array}$} & May 1 & 0 & 100.0 & 0 & 0 & 0 & 0 & 0 & 0 & 100 \\
\hline & May 10 & 8.6 & 56.5 & 21.7 & 4.4 & 0 & 4.4 & 0 & 4.4 & 100 \\
\hline & May 27 & 2.0 & 67.4 & 26.6 & 2.0 & 2 & 0 & 0 & 0 & 100 \\
\hline \multirow{3}{*}{$\begin{array}{l}\text { Control river section } \\
\text { No. } 3\end{array}$} & May 1 & 15.0 & 57.5 & 20.0 & 2.5 & 5.0 & 0 & 0 & 0 & 100 \\
\hline & May 10 & 0 & 100.0 & 0 & 0 & 0 & 0 & 0 & 0 & 100 \\
\hline & May 27 & 0 & 0 & 0 & 0 & 100.0 & 0 & 0 & 0 & 100 \\
\hline \multirow{3}{*}{$\begin{array}{l}\text { Control river section } \\
\text { No. } 4\end{array}$} & May 1 & 0 & 28.6 & 57.2 & 0 & 0 & 0 & 14.2 & 0 & 100 \\
\hline & May 10 & 5.3 & 71.1 & 21.1 & 2.5 & 0 & 0 & 0 & 0 & 100 \\
\hline & May 27 & 0 & 36.8 & 31.6 & 15.8 & 10.5 & 0 & 5.3 & 0 & 100 \\
\hline
\end{tabular}


According to the data of the control fishing, it was established that the ichthyofauna was represented by typical species for the Lower Irtysh: with the dominance of cyprinids: roach (Rutilus rutilus Linnaeus), ide (Leuciscus idus (Linnaeus)), dace (Leuciscus leuciscus Linnaeus), bream (Abramis brama Linnaeus), crucian carp (Carassius carassius Linnaeus), goldfish (Carrassius auratus Linnaeus). Percidae were represented by 3 speci- es: perch (Perca fluviatilis Linnaeus), ruff (Gimnocephalus cernuus Linnaeus), zander (Sander lucioperca Linnaeus). Among the valuable fish, representatives of sturgeon were noted: sterlet (Acipenser ruthenus Linnaeus), Siberian sturgeon (Acipenser baerii Brandt) and representatives of coregonids: inconnu (Stenodus leucichthys nelma Pallas). One species of Esocidae was noted: pike (Esox lucius Linnaeus) and burbot.

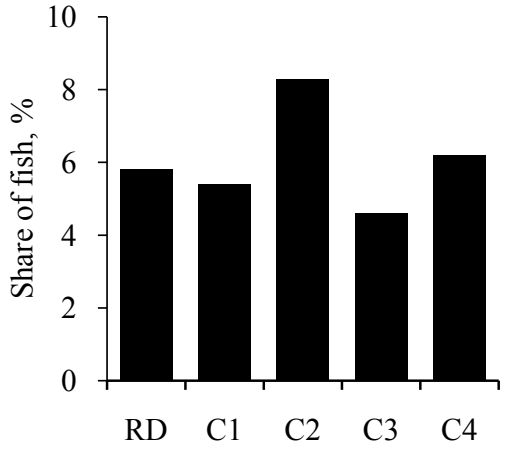

$a$

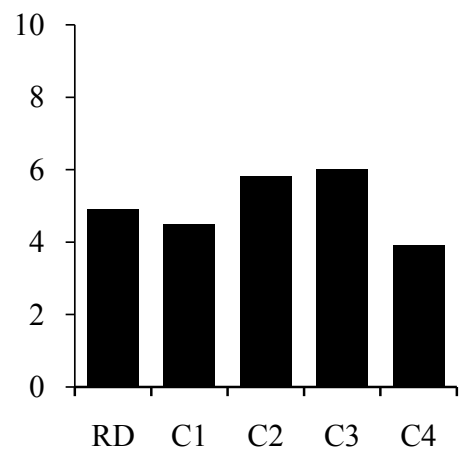

River sections

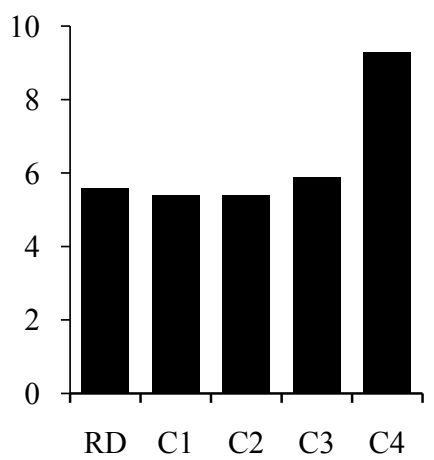

Fig. 4. Percentage of group sturgeon recorded by the hydroacoustic method in the water areas of the studied sections of the Irtysh River: $a$-May 1; $b$-May 10; $c$-May 27; RD - Riverbed depression; $\mathrm{C} 1$-Control river section No. 1; $\mathrm{C} 2$-Control river section No. 2; C3 - Control river section No. 3; C4 - Control river section No. 4

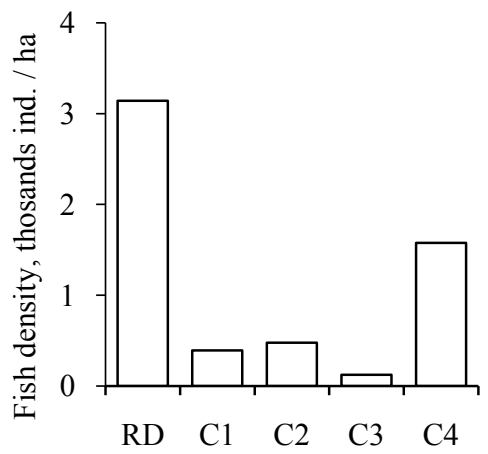

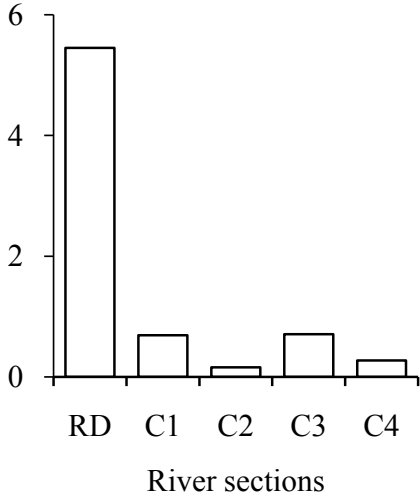

River sections

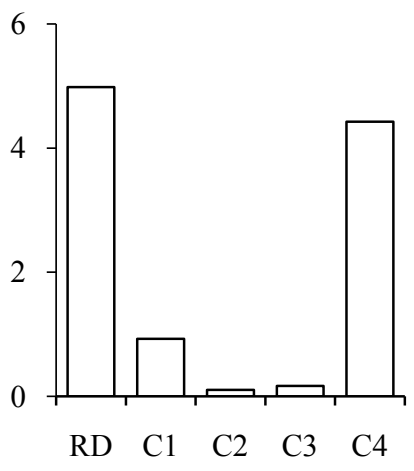

Fig. 5. Fish density recorded by the hydroacoustic method in the water areas of the studied sections of the Irtysh River: $a-$ May $1 ; b-$ May 10 ; $c$-May 27; RD-Riverbed depression; $\mathrm{C} 1$ - Control river section No. 1; C2 - Control river section No. 2; C3 - Control river section No. 3; C4 - Control river section No. 4

According to the results of echometric sounding of the studied river sections, it was found that the size and taxonomic composition of the ichthyofauna, as well as the fish density, differed. When studying the water area of the riverbed depression on May 1 , it was found that the share of sturgeon was 5.8, the share of other fish species was 94.2\% (Fig. 4). Among other fish species, the dominant group was always represented by cyprinids. Over $2 / 3$ of sturgeon belonged to size groups 5-10 and 10$15 \mathrm{~cm}$, their share amounted to $44.5 \%$ and $26.5 \%$, respectively. The shares of size groups $<5,15-20,20-25,25-30,30-35$ and $>35 \mathrm{~cm}$ were $6.5,7.7,5.2,2.5,3.2$ and $3.9 \%$ respectively (Table). The fish density was 3,141 individuals/ha (Fig. 5).

The distribution of fish size groups and the share of sturgeon in the waters of the control sections differed from the water area of the riverbed depression. The study of the control section No. 1 (C1) showed that the group of sturgeon was represented by individuals with body sizes $<5,5$ $10,10-15,15-20,20-25$ and $>35 \mathrm{~cm}$, their shares were $16.7 \%, 50.1 \%$ and $8.3 \%$, respectively, in the last 4 size groups (Table 1). In the investigated area, the fish density index was $391 \mathrm{ind} . / \mathrm{ha}$, and the share of sturgeon from all registered fish was $5.4 \%$ (Fig. 4, 5).

In the water area of the control section No. 2 (C2), the share of sturgeon was $8.3 \%$, while it was completely $(100 \%)$ represented by the size group $-5-10 \mathrm{~cm}$ (Table 1). The fish density was an order of magnitude lower than in the water area of the riverbed depression -476 ind./ha (Fig. 4, 5). The study of the water area of the control section No. 3 (C3) showed that the presence of the following size groups was noted for sturgeon : $<5,5$
$10,10-15,15-20$ and $20-25 \mathrm{~cm}$, their shares were 15.0, 57.5, 20.0, 2.5 and $5.0 \%$ respectively. The total share of sturgeon was $4.6 \%$ of the total number of fish recorded in this area, and the value of fish density was 124 ind./ha (Fig. 4, 5).

Analysis of the structure of the fish population in the water area of the control section No. 4 (C4) also revealed that sturgeon were represented by size groups of 5-10, 10-15 and 30-35 cm, their shares amounted to $28.6 \%, 57.2 \%$ and $14.2 \%$ (Table). In the water area of the $\mathrm{C} 4$ site, the fish density was the highest of all the control sections $-1,577 \mathrm{ind}$./ha, and the share of sturgeon among the total number of fish was $6.2 \%$ (Fig. 4, 5).

An analysis of the hydroacoustic survey carried out on May 10 also revealed a difference in the size structure of the fish population of the riverbed depression and the control sections. In the water area of the riverbed depression, the share of sturgeon was $4.9 \%$, the share of other species $-95.1 \%$ (Fig. 4). The size structure was as follows: the proportions of size groups $<5,5-10,10-15,15-20,20-25,25-30,30-35$ and $>35 \mathrm{~cm}$ were $5.8,50.6,30.0,7.0,7.1,4.3,0.3,0.9$ and $0.3 \%$, respectively (Table). The fish density was 5,450 ind./ha (Fig. 5). In the water area of the control section $\mathrm{C} 1$, sturgeon were completely represented by the group with body size of $10-15 \mathrm{~cm}$ (Table), while the value of their share of the total number of fish was $4.5 \%$, fish density was 689 ind./ha (Fig. 4, 5).

Analysis of the taxonomic and size structure of fish in the water area of the control section $\mathrm{C} 2$ also revealed some differences from the area of the riverbed depression. In the sturgeon group, individuals with body sizes of $20-25$ and $30-35 \mathrm{~cm}$ were absent. The proportions of size groups $<5$, 
$5-10,10-15,15-20,25-30$ and $>35 \mathrm{~cm}$ were $8.6 \%, 56.5 \%, 21.7 \%$ and $4.4 \%$ each in the last three size groups, respectively (Table 1). The fish density in this area was $158 \mathrm{ind}$./ha, and the share of sturgeon among the total number of fish was $5.8 \%$ (Fig. 4, 5).

According to the results of hydroacoustic surveys in the water area of the control section $\mathrm{C} 3$, it was established that sturgeon were represented only by the size group 5-10 $\mathrm{cm}(100 \%)$, and their share of the total fish population in the study area was comparable to that of the control section C2 $-6.0 \%$. The fish density was 706 ind./ha (Fig. 5).

As a result of the analysis of the data of echometric sounding of the water column in the area of the control section $\mathrm{C} 4$, it was found that among the sturgeon, the largest individuals with body sizes of 20-25, 25$30,30-35$ and $>35 \mathrm{~cm}$ were not recorded. Shares of size groups $<5,5$ $10,10-15$ and $15-20 \mathrm{~cm}$ were $5.3 \%, 71.1 \%, 21.1 \%, 2.5 \%$, respectively (Table). In the water area of the control section $\mathrm{C} 4$, the fish density was 272 ind./ha, while the share of sturgeon was 3.9\% (Fig. 4, 5).

As a result of the analysis of the hydroacoustic survey carried out on May 27, differences were also noted in the size and taxonomic structure of the fish population of the riverbed depression and the control sections of the river. In the water area of the riverbed depression, the share of sturgeon was $5.6 \%$, the share of other fish species was $94.4 \%$, respectively (Fig. 4,5 ). The shares of the size groups of sturgeon $<5,5-10,10-15,15-20,20-25$, $25-30,30-35$ and $>35 \mathrm{~cm}$ were $2.9,52.2,32.4,6.8,2.1,0.7,1.1$ and $1.8 \%$, respectively (Table 1 ). In the water area of the riverbed depression, the fish density was 4981 ind./ha (Fig. 5).

In the water area of the control section C1, the share of sturgeon was $5.4 \%$ of the total fish population (Fig. 4). For this group of fish, large individuals with body sizes of 20-25, 25-30, 30-35 and $>35 \mathrm{~cm}$ were not recorded. The shares of size groups $<5,5-10,10-15$ and $15-20 \mathrm{~cm}$ were $8.2 \%, 69.4 \%, 18.3 \%$ and $4.1 \%$, respectively (Table). In the water area of this section (C1), the fish density was 926 ind./ha (Fig. 5).

Analysis of hydroacoustic survey data in the control section C2 showed that sturgeon were represented by size groups $<5,5-10,10-15$, $15-20$ and $20-25 \mathrm{~cm}$, their shares were $2.0,67.4,26.6,2.0$ and $2.0 \%$ respectively. Individuals with body sizes of $25-30,30-35$, and $>35 \mathrm{~cm}$ were absent (Table 1). The fish density was the lowest of all control sections for the entire observation period - 102 ind./ha, while the share of sturgeon from the total number of registered fish was 5.4\% (Fig. 4, 5).

In the water area of the control section $\mathrm{C} 3$, the share of the sturgeon group was $5.9 \%$ (Fig. 4). Sturgeon were represented only by one size group 20-25 cm (Table). The fish density was $166 \mathrm{ind}$./ha (Fig. 5). According to the results of the analysis of echometric sounding of the water column in the area of the control section $\mathrm{C} 4$, it was found that the share of the sturgeon was $9.3 \%$ (Fig. 4). This group of fish was represented by individuals with body sizes of 5-10, 10-15, 15-20, 20-25 and 30-35 cm, their shares were $36.8,31.6,15.8,10.5$ and $5.3 \%$, respectively, of the total number of these fish in the water area of the control section C4 (Table). The fish density value was most comparable with this indicator in the water area of the riverbed depression, and its value was 4,423 ind./ha (Fig. 5).

The average density of the fish population in the study period in the water area of the riverbed depression was 4,524 ind./ha, and in the water areas of the control sections (C1-C4): 669, 245, 332 and 2,091 ind./ha, respectively (Fig. 6). As a result of the performed one-way analysis of variance according to the average fish density in the water areas of the control sections of the river and in the section of the riverbed depression, the presence of a significant difference effect in terms of density was established $(\mathrm{F}=4.949, \mathrm{P}=0.018)$. Further comparative analysis based on the Tukey criterion in terms of fish density showed a statistically significant difference between the section of the riverbed depression and 3 control sections of the river: $\mathrm{C} 1(\mathrm{P}=0.012), \mathrm{C} 2$ and $\mathrm{C} 3(\mathrm{P}=0.006$ and $\mathrm{P}=$ $0.007)$, when analyzed with the section $\mathrm{C} 4$ no statistically significant difference was noted $(\mathrm{P}=0.129)$.

\section{Discussion}

Clouds of increased turbidity or so-called "boiling clouds" are observed in the water area of the investigated riverbed depression because of the interaction of multidirectional currents and features of the channel morphology (Chemagin, 2018). This phenomenon is associated with the influx of a large number of suspended particles from the bottom layers of the water flow horizon as a result of the action of powerful turbulent pulsations of the river flow velocity. Studies of this phenomenon have shown (Baryshnikov, 2007) that it is associated with large-scale eddy turbulent structures that transport suspended particles from the bottom to the column to the water surface. Fish can avoid turbulent flows, in which chaotic and wide fluctuations in velocity are observed, and, on the contrary, can be attracted to flows with a predictability component (Liao \& Cotel, 2012). In addition (Liao \& Cotel, 2012) fish can save energy in turbulence by using two different, though not mutually exclusive mechanisms: the use of areas with reduced flow and capture of vortex (use of the energy of discrete vortices). Most likely, the aggregations of fish in the water area of the riverbed depression despite the complex turbulent environment, is also due to the predictability of the flow in the form of vertical vortices - circulations, as well as the presence of low-velocity flow zones (malfunctioning currents, zones located downstream of the vortices). The presence of lowvelocity sections, or sections of "hydrodynamic shadow" in the water area of riverbed depressions was shown (Mochek et al., 2019) based on the analysis of hydroacoustic studies of distribution of the fish and morphology of the bottom in the lower reaches of the Irtysh River. The use of zones of low-velocity in the stream to hold the station helps fish individuals to maintain their position in the stream relative to the Earth's coordinate system without active swimming (Gerstner, 1998), adjusting their own position with reduced movements of the body and fins (Liao \& Cotel, 2012). Additionally, it was found that fish show preferences for some turbulence regimes (Cotel et al., 2006); this, in turn, explains the statistically reliably higher fish densities in the water area of the turbulent section of the riverbed depression, in comparison with the control (laminar) sections with predominantly rectilinearly directed currents.

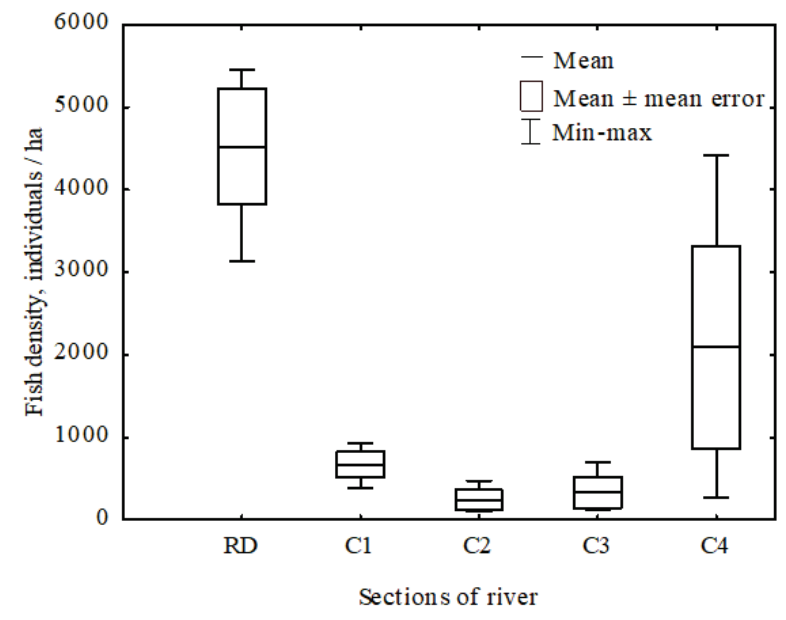

Fig. 6. Average fish density in the water areas of the studied areas of the Irtysh River (May, 2020): RD - Riverbed depression;

$\mathrm{C} 1$ - Control river section No. 1; C2 - Control river section No. 2; C3 - Control river section No. 3; C4 - Control river section No. 4

The formation of concentrations of various fish species, including sturgeon in the water areas of riverbed depressions, can be beneficial both from the point of view of shelter from predators in zones of increased turbidity (Wishingrad et al., 2014), and to save energy resources in the zones of low-velocity, which are formed in the presence of vertical vortex structures. It should be noted (Yuan et al., 2016; Duan et al., 2017) that individuals of the Siberian sturgeon have relatively high swimming performance and a relatively low coefficient of resistance due to the unique body shape, as well as a high ability to cope with oxygen deficiency, while individuals of this species, as well as individuals of sterlet, concentrate in riverbed depressions. Siberian sturgeon has a wide range of reaction rates, which allows it as a species to occupy vast territories and form life strategies inherent in populations inhabiting an environment characterized by different conditions (Ruban, 2019).

In conditions of high water transparency, representatives of sturgeon (Acipenser fulvescens Rafinesque) make significant movements, i.e. escape from predators; in zones of increased turbidity, the risk of death from a predator decreases, as a result, the escape distance becomes less signifi- 
cant (Wishingrad et al., 2014). Thus, the formation of aggregations of fish in the water areas of riverbed depressions, i.e. the use of their structural heterogeneity due to the presence of multidirectional currents and the resulting increased turbidity (Minello \& Benfield, 2018) can be a relatively beneficial strategy of shelter from predators from a bioenergetics point of view (Wishingrad et al., 2014). It is in the water area of the riverbed depression that among sturgeon in almost all periods individuals of all sizes are noted, including the largest, i.e. aggregations are formed from different-sized and, accordingly, different-age groups of fish, in contrast to the control sections. This pattern may arise as a result (Liao \& Cotel, 2012) of the use by fish, including sturgeons, of the energy of discrete vortices, the use of low-velocity zones (Mochek et al., 2019), and also due to the preference for some turbulence regimes (Cotel et al., 2006).

The presence of flow turbulence in the studied section of the river forms a heterogeneity of the environment, as a result of which aggregations of fish are observed in the water area of riverbed depressions during the period of open water (Pavlov et al., 2006; Borisenko et al., 2013). It is worth noting (Pavlov et al., 2006; Mochek et al., 2019) that the riverbed depressions of the Lower Irtysh play a multifunctional role as places of year-round concentration of fish, including juveniles, which in turn allows them to be detected and recorded by the hydroacoustic method.

The peculiarity of the environment of the riverbed depression also allows the formation of aggregations of cyprinids, in the presence of predators (perch, pike perch, nelma and pike), since the turbulence of the flow and turbidity of the water caused by the peculiarity of the hydraulics of the channel of the studied section of the river can be used by prey for shelter from predatory fish (Wishingrad et al., 2014, Ajemian et al., 2015; Sohel et al., 2017; Minello \& Benfield, 2018).

\section{Conclusion}

Thus, it has been established that in river sections with complex multidirectional currents, which characterize the flow as turbulent, i.e. in the water areas of the riverbed depression, concentrations of fish of increased density are formed with the share of fishes of the Acipenseridae family from $4.9 \%$ to $5.8 \%$. Moreover, sturgeon in the section of the riverbed depression are represented by individuals of different sizes and ages, in contrast to the control sections, in which individuals with a body size of more than $25-30 \mathrm{~cm}$ were rarely observed. The fish density in the riverbed is statistically significantly higher in comparison with the water areas of the control areas with a predominantly rectilinear flow characterizing them as laminar.

\section{References}

Ajemian, M. J., Sohel, S., \& Mattila, J. (2014). Effects of turbidity and habitat complexity on antipredator behavior of three-spined sticklebacks (Gasterosteus aculeatus) Environmental Biology of Fishes, 98(1), 45-55.

Altenritter, M. E., Wieten, A. C., Ruetz, C. R., \& Smith, K. M. (2013). Seasonal spatial distribution of juvenile lake sturgeon in Muskegon Lake, Michigan, USA. Ecology of Freshwater Fish, 22, 467-478.

Andrews, S. N., O’Sullivan, A. M., Helminen, J., Arluison, D. F., Samways, K. M., Linnansaari, T., \& Curry, R. A. (2020). Development of active numerating sidescan for a high-density overwintering location for endemic shortnose sturgeon (Acipenser brevirostrum) in the Saint John River, New Brunswick. Diversity, $12(1), 23$.

Baryshnikov, N. B. (2007). Dinamika ruslovykh potokov [Dynamics of channel flows]. RGGMU, Saint Petersburg (in Russian).

Bogdanov, V. D., \& Mel'nichenko, I. P. (2011). Rol' zimoval'nykh yam r. Lyapin dlya sigovykh ryb [Role of riverbed wintering depressions of the Lyapin River for coregonids]. Agramyy Vestnik Urala, 86, 48-49 (in Russian).

Borisenko, E. S., Mochek, A. D., Pavlov, D. S., \& Chemagin, A. A. (2013). Distribution of fish in the river system of the lower Irtysh. Journal of Ichthyology, 53(1), $16-27$.
Borisenko, E. S., Mochek, A. D., Pavlov, D. S., \& Degtev, A. I. (2006). Hydroacoustic characteristics of mass fishes of the Ob-Irtysh basin. Journal of Ichthyology, $46(2), 227-234$.

Chemagin, A. A. (2018). Osobennosti gidravliki rechnykh uchastkov ruslovykh zimoval'nykh yam reki Irtysh v period otkrytoy vody [Features of hydraulics of the river sectors with riverbed wintering holes of the Irtysh in open water period]. Bulletin of the Astrakhan State Technical University, Fisheries, 2018, 60 69 (in Russian).

Cotel, A. J., Webb, P. W., \& Tritico, H. (2006). Do brown trout choose locations with reduced turbulence? Transactions of the American Fisheries Society, 135(3), 610-619.

Duan, M., Qu, Y., \& Zhuang, P. (2017). Swimming characteristics of the Siberian sturgeon. In: Williot, P., Nonnotte, G., Vizziano-Cantonnet, D., \& Chebanov, M. (Eds.). The Siberian sturgeon (Acipenser baerii, Brandt, 1869). Volume $1-$ Biology. Springer. Pp. 229-246.

Elder, J., \& Coombs, S. (2015). The influence of turbulence on the sensory basis of rheotaxis. Journal of Comparative Physiology A, 201(7), 667-680.

Gerstner, C. L. (1998). Use of substratum ripples for flow refuging by Atlantic cod, Gadus morhua. Environmental Biology of Fishes, 51(4), 455-460.

Holubová, M., Čech, M., Vašek, M., \& Peterka, J. (2019). Density dependent attributes of fish aggregative behaviour. PeerJ, 7, e6378.

Liao, J. C., \& Cotel, A. (2012). Effects of turbulence on fish swimming in aquaculture. In: Palstra, A. P., \& Planas, J. P. (Eds.). Swimming physiology of fish. Springer. Pp. 109-127.

Marenkov, O. N. (2018). Ecological and biological aspects of zander and Volga zander reproduction under conditions of the Zaporizhzhia reservoir (Ukraine). Ukrainian Journal of Ecology, 8(1), 441-450.

Minello, T., \& Benfield, M. (2018). Effects of turbidity on feeding of southem flounder on estuarine prey. Marine Ecology Progress Series, 594, 203-212.

Mochek, A. D., Borisenko, E. S., \& Pavlov, D. S. (2019). Winter fish distribution in the riverbed depression in the Urtysh River. Journal of Ichthyology, 59(3), 352-357.

Muška, M., Tušer, M., Frouzová, J., Draštík, V., Čech, M., Jůza, T., Kratochvíl, M., Mrkvička, T., Peterka, J., Prchalová, M., Říha, M., Vašek, M., \& Kubečka, J. (2013). To migrate, or not to migrate: Partial diel horizontal migration of fish in a temperate freshwater reservoir. Hydrobiologia, 707, 17.

Nakayama, S., Doering-Arjes, P., Linzmaier, S., Briege, J., Klefoth, T., Pieterek, T., \& Arlinghaus, R. (2018). Fine-scale movement ecology of a freshwater top predator, Eurasian perch (Perca fluviatilis), in response to the abiotic environment over the course of a year. Ecology of Freshwater Fish, 27(3), 798-812.

Pavlov, D. S., Mochek, A. D., Borisenko, E. S., Degtev, A. I., Shakirov, R. R., \& Degtev, E. A. (2006). Biological significance of the Gornoslinkinskaya riverbed depression in the Irtysh. Joumal of Ichthyology, 46(2), S125-S133.

Pavlov, D. S., Mochek, A. D., Borisenko, E. S., Degtev, E. A., \& Degtev, A. I. (2010). Irregularities of the bottom and fish aggregations on a stretch of the Irtysh. Journal of Ichthyology, 50(11), 997-1001.

Ruban, G. I. (2019). Adaptive ecological and morphological features of the Siberian sturgeon (Acipenser baerii Brandt). Inland Water Biology, 12(2), 210-216.

Sohel, S., Mattila, J., \& Lindström, K. (2017). Effects of turbidity on prey choice of three-spined stickleback Gasterosteus aculeatus. Marine Ecology Progress Series, 566, 159-167.

Thayer, D., Ruppert, J. L. W., Watkinson, D., Clayton, T., \& Poesch, M. S. (2017). Identifying temporal bottlenecks for the conservation of large-bodied fishes: Lake sturgeon (Acipenser fulvescens) show highly restricted movement and habitat use over-winter. Global Ecology and Conservation, 10, 194-205.

Westrelin, S., Roy, R., Tissot-Rey, L., Bergès, L., \& Argillier, C. (2017). Habitat use and preference of adult perch (Perca fluviatilis L.) in a deep reservoir: Variations with seasons, water levels and individuals. Hydrobiologia, 809(1), 121-139.

Wishingrad, V., Chivers, D. P., \& Ferrari, M. C. (2014). Relative cost/benefit trade-off between cover-seeking and escape behaviour in an ancestral fish: The importance of structural habitat heterogeneity. Ethology, 120, 973-981.

Yuan, X., Cai, L., Johnson, D., Tu, Z., \& Huang, Y. (2016). Oxygen consumption and swimming behavior of juvenile Siberian sturgeon Acipenser baerii during stepped velocity tests. Aquatic Biology, 24(3), 211-217.

Yudanov, K. I., Kalikhman, I. L., \& Tesler, V. D. (1984). Rukovodstvo po provedeniyu gidroakusticheskikh s'emok [Guidelines for hydroacoustic surveys]. VNIRO, Moscow (in Russian).

Zimmerman, D., Pavlik, C., Ruggles, A., \& Armstrong, M. P. (1999). An experimental comparison of ordinary and universal kriging and inverse distance weighting. Mathematical Geology, 31(4), 375-390. 